\title{
Dangerous Bodies: \\ Blackness, Fatness, and the Masculinity Dividend
}

\author{
Marta Usiekniewicz \\ University of Warsaw
}

\begin{abstract}
Contemporary obesity epidemic discourse galvanizes racism and classism under the veil of "care," and is used to further stigmatize mostly poor people of color. I examine the intersection of fatness, race, and masculinity to show how in the case of black male bodies fatness is criminalized and used to legitimize excessive violence inflicted on those bodies. I discuss the oftentimes conflicting projections attached to fat black male bodies to analyze the mechanism that enable not just the criminalization of race and poverty, but also of fatness in the American culture of personal responsibility. I also discuss the unacknowledged racial and gender biases or fat studies, which partially impede the analysis of non-white non-female bodies.
\end{abstract}

Key words: race, masculinity, fatness, masculinity dividend, disability

You know, I'm not at all sure that we are the ones who are being hurt the most. In fact I'm sure we are not. We are the ones who are dying fastest.

- James Baldwin in Esquire interview

According to Killed by Police, an independently run website aggregating all instances of civilian deaths at the hands of law enforcement officers, 1081 mostly non-white people died as a result of officer-involved incidents in the United States in the year 2014 alone. Such staggering statistics, combined with the numerous reports of officers not facing punishment, for example in the cases of Tryvon Martin, Michael Brown, and Eric Garner, have created an atmosphere of racial tension, which culminated in public protests (e.g. in Ferguson, MI), the rise of new social movements (e.g. the Black Lives Matter campaign), as well as other forms of resistance against the systemic racism diagnosed in the American judiciary and penitentiary systems.

One of the better-known cases was the death of a New Jersey resident, Eric Garner, who was choked to death for illegally selling cigarettes. His death sparked another campaign under the slogan "We Can't Breathe." In an episode of The Daily Show called "We Can't Breathe" following the 
failure to indict Eric Garner's killer, Jon Stewart summarized the coverage and explanations offered for Garner's death in the following way: "So we've established that the police used appropriate force for the dangerously large, but incredibly fragile, out of shape monster weakling" (emphasis added). Stewart was referring to the paradoxical accounts that had attempted to explain Garner's death away and justify the violence he experienced. On the one hand, to justify the need for six arresting officers, Garner was depicted as a very big and strong man whose aggressive behavior mandated extreme force. At the same time, Congressman Peter King (R), in an interview for CNN, claimed that Garner had died because of his obesity and related health issues: asthma and a heart condition. According to King, it was these illnesses that caused Garner's death, not the illegal chokehold performed by one of the arresting officers (Khazan 2014). In his customary style, Stewart highlighted the conflicting images attached to big black bodies in the media.

Though challenged on their reliance on racist tropes, including the image of the scary black man with superhuman strength (Bouie 2014), most conservative defenses of police actions were not criticized for their sizeist and ableist assumptions. ${ }^{14}$ The misrepresentation and criminalization of African Americans as a means of legitimizing violence against them and their incarceration has been an established practice in the United States since the abolition of slavery, throughout the Reconstruction and the Jim Crow era, ${ }^{15}$ the conservative turn of the late 1970s and 1980s, the war on drugs, and especially now, with the rise of the Prison Industrial Complex in which bodies of color have become commodities necessary for the business model to prosper (Ben-Moshe 2013: 137). ${ }^{16}$ Thus imagined as hyperstrong, hypersexual, and inherently evil, black men in the United States have been equated with criminality and therefore as requiring constant surveillance and preemptive violence. $^{17}$

\footnotetext{
${ }^{14}$ There are notable and important exceptions to this silence that have inspired this article. Frank M. Perry in "When disability and race intersect" comments on the intersection of race and disability, and the "failure of law enforcement to accommodate disability." He continues by saying that "Garner's case is not the first to suffer from these deadly intersections [race and disability] -- the language we've heard echoes numerous other cases in which police and their defenders blame disability for the results of police violence." Melissa McEwan in "Today at an Intersection of Racism and fat Hatred" discusses the how sizeism contributes and intersects with racial oppression.

${ }^{15}$ See also Morris Targeting Black Masculinity: An Analysis of the (mis)Representation of Black Men in the History of Early American Popular Culture.

${ }^{16}$ See also Alexander's The New Jim Crow: Mass Incarceration in the Age of Color Blindness.

${ }^{17}$ In the Preface to Black Masculinity and Sexual Politics, Anthony J. Lemelle notes that the representation of black masculinity has been traditionally limited to two oppositional tropes: the hypersexualized or the effeminate and the sources of these images were sought in the period of slavery and its immediate aftermath. Lemelle asserts that in fact black masculinity is a "major U.S. industry" and that hierarchies are
} 
At the same time, the black man in America has been continuously depicted as morally and intellectually inferior: a masculinity in perpetual self-inflicted crisis, which garners no sympathy in the American mainstream culture of personal responsibility. One aspect of this image that has been overlooked in discussions of black masculinity, however, is the way in which the notions connected with fatness and illness play into representations of black male corpulence. Given that among the 1081 dead in 2014 the majority were men of color, it seems that those black male bodies usually connected with a threat of violence are also, at the same time, vulnerable. ${ }^{18}$ Not just as targets of police brutality, but also as fat-shamed and fat-oppressed bearers of another body-stigmatizing feature: fatness. Within the contemporary obesity epidemic discourse-an heir to an earlier discourse of the "war on obesity" — which galvanizes racism and classism under the veil of "care" (Berlant 2011: 102), failure to fit an arbitrary norm of a "healthy size" is used to further stigmatize mostly poor people of color (Biltekoff 2007: 39-43). As a result, fitness and able-bodiedness become markers of class and citizenship, further justifying the discrimination of those who do not meet the prescriptive paradigms of embodiment. It seems that it is the confluence of weakness and threat ascribed to corpulent black male bodies in a culture of personal responsibility that legitimates a lack of concern and a disregard for black lives.

Thus it would seem that critical tools developed by fat studies and disability studies could work to account for the mechanisms of exclusion that render black men and women vulnerable. At the same time, as noted by Ben-Moshe about disability studies, and Amy Erdman Farell about fat studies, both fields have suffered from an inability to see through their own racial and gender biases, though it appears that the former has acknowledged its lacuna much quicker than the latter. This is why in the upcoming sections I will focus on analyzing the ways in which fat studies have been ignoring masculinity and race in their research of fat hatred and sizeism, as well as ways in

results of "fleeting situational hegemonies" (2010: xii). Lemelle's take also enables a less homogenizing approach to black masculinity. Though I find his criticism of the approach chosen in this text informative, I believe that there are ways in which the analysis of the evolution of cultural tropes may help the broader social analysis of individual masculine embodiments and experiences.

${ }^{18}$ During a plenary session titled "Precarity and the Politics of the Nation: Settler States, Borders, Sovereignty" at the NWSA 36th Annual Conference in Milwaukee, November 13, 2015, Lisa Marie Cacho, discussing the case of $\mathrm{CeCe} \mathrm{McDonald}$, a trans-woman of color, observed that though black men fail to receive justice they are nevertheless recognized as legitimate victims of crimes, while women of color and trans people do not even merit the illusion of justice. I agree with that statement and argue that it is the constant victimization and criminalization of black men that renders them intelligible to the justice system. At the same time this system refuses to acknowledge other non-male victims; gender is a key element in criminalization, as well as victimization and recognition of those who suffer from the systemic racism present in the US judiciary system. 
which the critical tools of this discipline may be salvaged to discuss the mechanisms of oppression that render black men easy targets of institutional violence.

Though fat studies scholars notice the intersectionality of fat oppression with race and class, rarely do they address these issues in depth, focusing on the - no less important - efforts to destigmatize fatness. Despite their professed investment in diversity, fat studies take up the positioning of bodies that are white, cis gender, female, and middle-class, thus ignoring the various ways in which fatness and the war waged against it affect men, people of color, trans people, and the poor. As such, scholars not identified with the discipline, such as Lauren Berlant, may offer insights that are less tainted with the predominant and often unacknowledged assumptions of whiteness and femininity underpinning a lot of fat studies research, though the researcher's own bias is also visible in her account. In Cruel Optimism Berlant introduces the concept of "slow death," which she defines as "the physical wearing out of a population in a way that points to its deterioration as a defining condition of its experience and historical existence" (2010: 95). It would seem then that for black people in the United States vulnerability to violence is just such an experience of existence. This consistent violence leads not just to slow death, but an "accelerated death" justified by the conflation of contradictory representations of black (and in some cases fat) bodies. ${ }^{19}$

\section{Gap One: Race, Fatness, and Civilization}

Richard Dyer observes that "whiteness . . . colonizes the stereotypical definitions of all social categories other than those of race. To be normal, even to be normally deviant (queer, crippled) is to be white" (1997: 6), ${ }^{20}$ which is true for most conceptualizations of fatness in Western history with the exception of studies of "savages" undertaken during the period of colonization concurrent with the rise of modern sciences of the body. In Obesity: The Biography, Sander L. Gilman (2010) provides an account of the medical condition of "morbid obesity" from ancient times ${ }^{21}$ to the $21^{\text {st }}$ century, focusing on how ancient ideas of medicine were absorbed into Western, predominantly

${ }^{19}$ It is also dangerous to homogenize individual people into groups, as not all black men will face the same oppression; neither will black women or the poor of any race. Nevertheless, such labels make visible the broader socio-cultural and political mechanisms.

${ }^{20}$ Race is investigated in contemporary disability and mad studies, as evidenced by Ben-Moshe's text or Lukin's "Disability and Blackness." Historically these fields of study were formed by white scholars and activists, while popular imagery of disability as the "worst quality of life" seemed the starkest when paired with the most privileged status of whiteness.

${ }^{21}$ For a discussion of the Ancient peoples becoming white, see Painter's The History of White People, specifically pages 1-15. 
Anglophone theories of nutrition, particularly in the United States. He outlines how corpulence, which up until the $20^{\text {th }}$ century was coded as masculine (or in historically accurate terms "neutral"), has been divided into good and bad fat, yet the definitions and significations of those categories have been context-dependent and shifting.

Gilman (2010) notes that within the racist discourse of colonization the "savage" body remained lean due to the demands of labor in the uncivilized society. When, however, those bodies were introduced to civilization, they become gluttonous. This in turn was attributed to the weakness of their minds, as opposed to the mind of the civilized men. This idea was so widespread until the $18^{\text {th }}$ century that in fact James Cook was surprised to find obese men in the native population of Tahiti (2010: 160-1). The projection of the "weak-minded savage" travelled into the $19^{\text {th }}$ century representations of Native Americans and was used as an argument against their humanity. The $19^{\text {th }}$ century also generated the first notions of raced fatness as specifically gendered, with the popularization of the discourse inspired by the figure of Saaratije Baartman of the South African Khoikhoi (Hottentot) tribe, whose women were known for their ample posteriors. Since the adipose black body contradicted the then popular image of the "noble savage" black fatness became a sign of degeneration (2010: 164-5). Cyril Percy Donnison, writing in 1930 in the field of tropical medicine, observed that "[a]diposity is rare in the primitive native but is seen occasionally in mild degree in towns and is common in the American Negro. ... Over-nutrition seems to be associated with the civilized state" (qtd. in Gilman 2010: 168). Therefore, the "corruption" of the black body by civilization was not meant as a proof of the problems of civilization, but of racial inferiority.

Racialized notions of obesity continued with ideas concerning some races being prone to diseases related to nutrition. Gilman notes that in the early $20^{\text {th }}$ century diabetes was called the "Jewish disease" and was attributed to the inferiority of the Jewish race, and specifically to affluent Jewish men who ate and drank excessively. Their illness, however, was connected not with their racial makeup, but with their abominable lifestyle (2010: 86). In a similar vein, later $20^{\text {th }}$ century notions of racialized obesity also focused on lifestyle choices rather than inherent degeneracy, thus connecting obesity to psychoanalytical interpretations of the failure of the family - an approach that had a significant impact on how black fatness was understood. Gilman observed that the perceived collapse of the African American family in the 1960s and 1970s led to 
understanding excessive body size not as beautiful or healthy but as a disease process that originated within the family and led to multiple somatic illnesses. The public discussion of the collapse of the 'black family' was the major precursor for the shift within that community toward seeing body size as a marker of illness. (2010: 106)

The meanings ascribed to fatness have changed over time, with some notions becoming forgotten only to resurface under a different guise. It had been common in the popular understanding of raced fatness to assume that in cultures marked by scarcity of resources bigness was coded as power, importance, or beauty. Similar claims were made about historical periods when consumptive diseases lead to a wasting away of bodies, hence a plump body was a sign of health (Gilman 2004: 11) - a notion inconceivable within the logic of the obesity epidemic. Such understandings led to popular explanations as to why women of color were supposedly less affected by body-policing practices addressed to white women.

Doris Witt observes that most discussions of black fat refer to women, whose fatness is naturalized as the embodiment of nurture: both as object of consumption (symbolically and sexually) and provider of food. "African American women have, then, always been 'presences' in discourses about food and U.S. identities, particularly in specular form as the naturalized fat body" (1999: 191). Despite conflicting images of "deviant" femininity often invoked by representations of Saartije Baartman, "black women have been situated as the 'natural' in the domain of eating disorders, there have been no discourses emanating from white culture in recent years that expressly target (and construe as 'unnatural') black female appetite" (1999: 191). It may be argued that because of the intersection of oppressions that affect the representation and discussions of black female bodies, fatness does not function as a separate category but as a part of female blackness itself, especially in the case of the Mammy-inspired stereotype. To some extent, the cultural obsession with the black female body has narrowed the discussion of black fatness to fat black women. In the discursive and critical realms, the fat black man appears sporadically and rarely as a specific object of study, except for instances where his racial otherness is used as a point of comparison for usually unmarked white masculinity. 
The predominantly white fat studies scholars tend to homogenize non-whiteness and share a common assumption that fat black bodies are policed less than white ones, while size is a nonstigmatized attribute celebrated in popular culture. Jerry Mosher refers to two male rap groups to justify such a claim:

African American culture has traditionally been accommodating to fat; as recent rap groups like the Fat Boys and as Sir Mix-A-Lot's hit single "Baby Got Back" (1992) attest, fat does not have to be a source of shame: it can be claimed and asserted as a positive sign of cultural difference. In this light, dieting may be viewed skeptically as an assimilationist attempt to conform to white culture's restrictive corporeal ideals. (Mosher 2001: 176) ${ }^{22}$

Resistance to the "tyranny of slenderness" is seen as active rejection of both the patriarchal demand for thinness and the white racist society's demand of assimilation. Nevertheless, it seems that racial minorities though responding to different manners of body policing are still affected by norms, which are unmarkedly white. Minority communities may also have their own sets of bodily norms that their members internalize, such as the wide hips and prominent buttocks expected of sexy black women mentioned by Mosher above. It is interesting that in order to suggest a lesser disciplining force in African American culture Mosher chose male voices to have authority over the fatness discourse. Though he is right to claim that there are differences in ways in which bodily norms are internalized in various communities, his homogenizing view takes away some of the gender specificity of the various black embodiments and the objectification of black women by black men.

This simplifying rendition of raced fatness, especially in the context of the "obesity epidemic" discourse singling out bodies of color, is not the only available approach. ${ }^{23}$ Berlant joins the criticism of the presentation of obesity as a crisis or epidemic, but her claim is that these metaphors allow for a miscasting of what she thinks is a fact of life in a capitalist society. Seeing the obsession with obesity as another iteration of a moral panic, ${ }^{24}$ as do other scholars, she reads it in the context

22 See Joan Morgan's "From Fly-Girls to Bitches and Hoes," where she points out the misogynistic objectification present in these "celebration" of black beauty in hip hop.

${ }^{23}$ See also LeBesco, Revolting Bodies?: The Struggle to Redefine Fat Identity.

24 "Obesity has today triggered a moral panic, much as did AIDS in the 1980s, with real political and social 
of contemporary labor organization and unequal distribution of wealth. Though all America is growing fatter, says Berlant, due to poor healthcare it is the working class and the subproletariat (often non-white) whose bodies are most affected. Meanwhile the food industry emaciates both the land and workers (abroad) to produce the food that, once highly processed, will reach the economically disenfranchised consumers (2011: 106-7). She asks:

How do we think about labor and consumer-related subjectivities in the same moment, since, in my view, one cannot talk about scandals of appetite ... without talking about the temporality of the workday, the debt cycle, and the consumer practice fantasy. ... [W] [Wat does it mean that African Americans and Latinos and Latinas are especially bearing this body burden along with the symbolic negativity long attached to it? (2011: 105)

Farrell adds that especially towards the end of the $19^{\text {th }}$ and the beginning of the $20^{\text {th }}$ centuries "[f]atness was a motif used to identify 'inferior bodies'-those of immigrants, former slaves, and women-and it became a telltale sign of a 'superior' person falling from grace. In today's terms, fat, if it had a color, would be black, and if it had a national origin, it would be illegal immigrant, nonU.S., and non-Western" (2011: 8). Yet it seems that fat studies' efforts to reconfigure race in their discussion of fat stigma remain a work in progress, with a handful of scholars addressing the issue without romanticizing the perceived black fat resistance. ${ }^{25}$

\section{Gap Two: Gender, Fatness, and Hyper(in)visibility ${ }^{26}$}

The other omission of fat studies has been a tacit assumption that fat is gendered female. In "Feminism and the Invisible Fat Man," Kirsten Bell and Darlene McNaughton offer a critique of this

implications. It is also evident that the impact of being overweight on health is real and our medical responses are determined as much by the developments of medical knowledge and technology as by the social meaning associated with the disease" (Gilman 2010: xii). See also Biltekoff's "The Terror Within" which deconstructs the specter of the obese racially othered American soldier.

${ }^{25}$ Though not free from the romanticizing gesture, Gross's "Phat," offers an interesting intervention, as do LeBesco's Revolting Bodies?: The Struggle to Redefine Fat Identity, and Doris Witt's Black Hunger, yet those accounts focus on black women more than men. Lee F. Monaghan in Men and The War on Obesity: $A$ Sociological Study discusses the story of Lenny, his only black respondent, and challenges some of the notions connected to black male size, while Biltekoff focuses on fat soldiers (see note 11).

${ }^{26}$ In The Hyper(in)visible Fat Woman: Weight and Gender Discourse in Contemporary Society, Gaily introduces the term "hyper(in)visibility" to talk about the way in which female fatness both attracts the attention of onlookers (i.e. is hypervisible), but at the same time renders fat women sexually non-attractive and therefore invisible in the logic of the heteronormative sexual marketplace. 
gender bias and trace the origins of that particular shortcoming. They claim that because early fat studies were written from a distinctly second wave feminist perspective that saw patriarchy as the source of fat oppression, there was no space for an account of male fatness in that conceptualization. Early fat studies commentators, including Orbach, Millman, Chernin, Lawrence, Spitzack, Wolfe, MacSween, and Bordo shared a conviction that the disdain for fatness is gendered and is a means of policing women's bodies, while leaving men's bodies alone. In fact, both Orbach and Chernin agreed that men's weight issues were insignificant, and men "reveled in their fatness" (Chernin qtd. in Bell and McNaughton 2007: 110):

By now it must be evident that the fat man has been spared this burden of negative symbolic meaning [attached to fatness] only because the fat woman has taken it on. ... It is because the fat man believes the imagery his own culture has created that he can gorge himself with impunity and strut about the pool with his bulging belly, while the fat women are all wearing blouses in the water. (Chernin qtd. in Bell and McNaughton 2007: 110-111)

As a result, most of the academic interest in fatness focused on women's embodiment and hence the signification and stigmatization of fat has been conceptualized with an assumption of a female body. Bell and McNaughton argue that the early fat studies and fat activism have unwittingly contributed to the image of femininity as dieting, body-discipline, and body-shame. What is more, the distinctly second wave origin of fat studies contributed to the disregard of the racial (as well as class and trans) issues discussed in previous section.

Though I agree that this second wave heritage is complicit in determining fat studies' focus on women's bodies, I disagree with Bell and McNaughton's thesis that it is not patriarchy that governs body-policing. In their understanding of the concept, patriarchy refers to a system that privileges what is male over that what is female. A more contemporary view of patriarchy sees it as a network of hierarchies that interweaves identity categories of sex, gender, sexual orientation, race, class, ethnicity, and ablebodiedness. bell hooks deems this system a "white supremacist capitalist patriarchy" (hooks 1992: 96), but I would also add heterosexist to this depiction, and keep the diagnosis that it is in fact patriarchy and its cronies that maintain the hierarchization of bodies also according to their weight. 
While not disavowing the two critics' rightful objections to mainstream fat studies practice nor rejecting earlier notions that fat is a feminist issue, it is important to see that fat oppression has been the experience of women, yet it did not turn into the present form of severe female body control in Western societies until the $20^{\text {th }}$ century. Like many other social categories, fatness has been constructed as feminine only recently, which does not mean that it has not been successfully naturalized and used as a weapon against women and men performing non-hegemonic masculinities. It is no coincidence that the shift in the gendering of obesity took place at the same time as the early $20^{\text {th }}$ century political and economic emancipation of women. Granting women some economic and political freedom necessitated the emergence of another form of policing: weight-watching.

Most historians of fatness agree that fat had been vilified in white men and women equally till the end of the $19^{\text {th }}$ century, though reduction ad campaigns of that time were already advertised according to specific genders. Nonetheless, around the 1920s there was a split, and discourses of fat entered what Stearns calls the "misogynist phase" that lasted till the 1960s (Bell and McNaughton 2007: 114). According to Gilman, by the 1940s the obese patient became a woman, whereas men's obesity was mentioned only in passing (2010: 113). Gilman quotes Harold Dearden's observation from 1927 to illustrate the shift and its quick naturalization: "To a man the affliction [fatness] is grave enough, but to a woman!-who save a woman shall attempt to measure its really dread significance" (2010: 5). Hence, the power of the misogynist phase in fat history combined with the feminist backlash launched by Orbach et al. solidified fatness as a woman's issue. As a result, even examinations that analyze male fatness necessarily address the issue of emasculation, effeminization, and infantilization by fat. Lee F. Monaghan summarizes this, saying that

fat oppression [is] a real, emergent process that is not tied to female bodies though it is aimed at bodies that are positioned as feminine (disgusting, despised, dependent, passive, unhealthy) regardless of their biological sex. Within this field of masculine domination-which is potentially injurious not only for particular women but also men whose bodies supposedly symbolize 'failed' manhood-it is hardly surprising that fat oppression is often trivialized. (2008: 6) 
Still, it is possible to see male fatness in positive terms. Lee Monaghan and Helen Malson show on the basis of their sociological research that for some men fatness is indeed connected to power and sexual appeal. This is especially true for their black respondent: "In these extracts being a 'big guy' is construed as masculine, connoting strength, an ability to 'look after yourself,' and heterosexual desirability. The 'big guy' is constituted as 'manly' such that 'bigness' works here to enhance hegemonic masculinity" (2013: 308). Likewise Mosher explains how fatness comes to signify power: "self-proclaimed kings of their castles whose layers of fat buffered them from the world and assimilated social turmoil into the more visual and understandable realm of individual corporeal deviance" (2001: 168).

Yet Monaghan and Malson observe that despite the symbolic power and importance implied in the occupation of more space, "[t]his construction of bigness as masculine is, however, highly subject and context specific. Such specificity is evidenced when, for example, the discursive regulation of gendered and racialized subjects interface to produce the 'big' bodies of black and/or workingclass men as problematically too masculine" (2013: 308). Bigness as power is a notion dating back to the image of adiposity as success. Fatness as success was later associated with images of early capitalist exploiters, who fattened on others' work and suffering. Their corpulence begun to represent undeserved power, status, and greed. To some extent it is that image of the fat male body that seems to trigger the extreme hate fat people receive today, yet paradoxically the hate is now often projected on the poor who are also seen as undeserving and greedy. Yet the corpulence-as-power interpretation of male fatness is possible due to the images of fatness stemming from the pre-misogynist period in fat history, where oftentimes "good fat" was associated with power and affluence. Thus, Gilman observes: "[w]e all sense that our society makes the obese or fat or corpulent body more visible because it does not fit. Yet this visibility is seen to have multiple, often conflicting meanings" (2004: 13).

Despite a certain protective layer with regards to fat masculinity, there exits an ever-moving arbitrary line that differentiates between the potentially "good fat" of power and social status, and "morbid obesity" perceived as "bad fat." This "bad fat" has been associated not only with poor health, but also with negative mental traits such as unchecked appetite, laziness, inertia, stupidity, and non-productivity (Gilman 2010: 23, 35-6). Both the "war on obesity" and "obesity epidemic" discourses latched on to the connection of fatness with ill health and non-productivity seen as its 
logical consequence. If in Berlant's model productivity is the measure of citizen's worth then seeing lack of productivity as inherent to fatness justifies the fat shaming discourses. Fat people are understood as useless in the capitalist society organized around production, thus fat contributes to a loss of citizenship defined as (re)productivity in a society.

The effects of fatness on masculinity are numerous, yet in the post-mysogynist era of fat-shaming these effects signify an othering, a non-hegemonic status. In men as in women, fatness represents "extraordinary consumption of everything, including space" (Gilman 2004: 29). ${ }^{\text {By }}$ the second half of the $20^{\text {th }}$ century fatness has began to signify a loss of status and power, as fat men in 1970 s representations connote both averageness and crisis of hegemonic masculinity (Mosher 2001: 1701). Fatness also signifies in terms of sexuality. According to Gilman "[h]ypersexuality [was] a quality ascribed to the premodern fat boy, but repressed in modernity" (2010: 24). The sexuality of fat men has been repressed to such an extent that in most modern renditions of fat masculinity a fat man is either infantilized or rendered asexual. ${ }^{27} \mathrm{He}$ is represented as less of a man according to a phallocentric patriarchy where the measure of masculinity corresponds to the length of a penis and the ability "to stick it" in consenting owners of various orifices. Fat men, whose penises are proportionally smaller, seem less manly (Mosher 2001: 170). Finally, the intense coding of fatness as feminine, also due to the collateral of the early fat activism of Orbach et al., contributed to the image of fat men as worse at performing masculinity.

\section{Black Masculinity vs Fat Studies}

Though complicit in perpetuating its unacknowledged racist and gender biased assumptions, fat studies methods have been applied with some success in analyses of the bodies of men and (to an extent) non-white women, which has neither romanticized nor homogenized those groups. Yet, even if fat studies have acknowledged their biases, the question remains if this critical lens can be applied to the analysis of black male fatness.

If the archive determines the outcome of a query, then what happens if the very tool designed for the analysis is unwittingly entrenched in racism? After all, most of the scholars mentioned so far

\footnotetext{
${ }^{27}$ I am using the term "asexual" to denote a person perceived as not having or inspiring in others any sexual desire. I am aware that the term is also a label for a sexual identity on the LGBTQA+ spectrum, but it is not a meaning that I am deploying here. Therefore, my observations about asexuality are not meant as comments on actual people identifying as As.
} 
wrote from a position of relative privilege: either as white men, or as white women writing within a women-empowering discipline of fat studies. For them blackness and masculinity have worked as the other that enables a discussion of a naturalized category. Thus far in the discipline, fat blackness rendered as exotic has been used to illustrate how meanings of fatness have been established and how fatness in the US context has gradually come to signify non-whiteness or noncitizenship (Biltekoff 2007: 40). Fat blackness as deviancy of body or mind has been used to denaturalize the connection of diet and virtue. Black fatness as scary bigness has been used to fortify the myth of slenderness as normativity. Finally, though fat studies have been invested in exposing the "obesity epidemic" discourse for its racism and classism partly due to the discipline's institutional ties with academia, those most affected by that discourse have rarely been represented. In a sense, fat studies is a paradox. As a discipline stemming from a social justice movement and feminist perspectives, it aims to challenge racism, sexism, ableism, and other forms of oppression. At the same time, as described above, its heritage as well as location within academia manages to perpetuate racism or disregard for racial and gender diversity. Nevertheless, fat studies methods seem to deconstruct the ways in which a certain image economy is invoked to justify the violence against black men in the United States. In the following sections I will attempt to show what fat studies methods may yield when used to analyze misrepresentations of fatness which fuel the already racist misrepresentation of black men.

\section{Black Masculinity in the US}

In order to examine how the category of fatness informs the category of black masculinity, it is crucial to understand the contemporary image of black masculinity in American society. There are three domains of (mis)representation: sexuality, violence, and productivity. In Marlon Riggs's documentary, Ethnic Notions (1986), Barbara Christian observes that cultural representations of blackness have shaped not just the contemporary perceptions of blackness, but also public policy and to some extent the ways black Americans see themselves. The film presents an analysis of the formation and evolution of racial stereotypes of black Americans, and comments on the way political events and changes found reflection in those tropes. Ethnic Notions begins with the account of the rise of the Sambo character in the 1820s and continues with the origins of other racial types, including the Mammy, the Pickaninny and the Coon. It shows how the changes in the political system and the abolition of slavery reshaped the antebellum figure of the docile and happy black slave into the post-Civil War dangerous, cunning and even savage Coon and animal- 
like Pickaninnies. In a similar vein, Susan Booker Morris (2011) presents the evolution of the image of black masculinity in the $19^{\text {th }}$ century, showing the transition from that of docility to that of threat. She reiterates Christian's observations that the abolition of slavery in the white supremacist society required a recasting of the figure of the black man to justify the suppression of his newly-gained (only in theory) political and economic agency.

Morris writes that the pre-Civil War account of black masculinity depicted black men "as lazy and childlike, docile and happy, in the role of servant. These misrepresentations served to disseminate the view of black men as well suited to slavery" (2011: 77). In time this figure of the Sambo also attained negative characteristics. He began to be perceived as gluttonous, lazy, and stupid. Farell notes that fatness especially in connection with stupidity were another means of perpetuating racial oppression, as they legitimized the degradation and humiliation of black men. She also suggest that these images, which come from vaudeville or minstrel productions, continue in contemporary film and television productions. She adds that "These controlling images link blackness, fatness, and the 'uncivilized body,' making it easy for (white) viewers to read these characters as silly and inferior" (Farell 2011: 75).

But the docile former slave is by no means the only figure to rise from the $19^{\text {th }}$ century racists representations. After the Civil War black men were reimagined as "brutes harboring a ready anger that threatened at any minute to erupt as violence against whites" (Morris 2011: 79). The assumption of a pending or brewing black vengeance became the justification for the preemptive violence inflicted on black men. However, the violent black male was not the only figure meant to legitimize violence towards black people. Patricia Turner observes that the representations of black children in constant peril also served that purpose: "there was a need to imagine black children as animal-like, as savage. If you do that . . . then it's much easier to rationalize and justify the threat that's embodied in having an alligator pursuing the child" (Ethnic Notions, 1986). Nursery rhymes such as "Ten Little $\mathrm{N}^{* * *}$ highlighted the perishability of black lives and the humor thereof.

The other component that sealed the image of threatening black masculinity was the specter of a violent and sexual threat against white women projected onto free black man. This image stemmed from a previous misrepresentation of black men as uncivilized, where civilization meant whiteness (see below). Lack of civilization was connected with not being in control of one's own urges 
(gastronomic or sexual), which lead to a depiction of black men as obsessed with consumption. It is no coincidence that the majority of depictions of black people in the $19^{\text {th }}$ and $20^{\text {th }}$ centuries, except for those associated with entertainment, came in the form of food packaging. Syrup, flour, tobacco, and black beans were all labeled with pictures of a smiling black faces. This was a nostalgic throwback to the "happy slave" paradigm, docile and content to serve a white family, devoted to procuring food.

Kyla Wazana Tompkins argues that these images conflated appetite for food with other appetites, also sexual (2011: 55). As a result, the smiling Sambo offering beans became the sexually threatening non-human whose favorite treat was virginal white women. The wide white smile that in earlier depictions symbolized docility and happiness became the gaping mouth that shall consume all. Tompkins observes that at the center of late $19^{\text {th }}$ century texts was "the constitution, protection, and reproduction of the chaste, white body; at the center of the project [was] the erotic and political life of the mouth. ... The mouth, a socially visible opening in the body, was one site where the threat of racial inversion and bodily dissolution lingered" (2011: 55). In a culture preoccupied with both the disciplining of white female sexuality and enslavement of black men, the perpetuation of the figure of the black sexual predator was a useful ideological device.

Inspired by treaties by Ida B. Wells and Frederick Douglas concerning lynchings as means of political control, Angela Davis suggested that the "justification" for these brutal public executions originated in the myth of the black rapist. The figure of the black sexual predator, combined with the widespread practice of white men raping black women, became "instrument[s] of racist terror" in the South (1983: 185) that fixed the characteristic of uncontrolled sexuality onto the racist stereotype of blackness. Black men represented the unmanly too-muchness with their uncontrollable lust and violence, while black women depicted as seductresses of white men were seen as having uncontrollable sexual appetite that mandated continuous and unacknowledged rape.

These hypersexual figures enabled Southern men, who experienced a perceived loss of status as a result of the shift in social and racial relations after the end of slavery and a shift of the masculine ideal from the Victorian gentleman to a tougher manhood, to vent their frustration by sexually abusing black women or physically abusing black men. Bederman notes that "by constructing black 
men as natural rapists and by resolutely and bravely avenging the (alleged) rape of pure white womanhood, Southern white men were able to depict themselves as ideal men: 'patriarchs, avengers, righteous protectors'" (Bederman 2011: 47). This construction enabled the justification of lynching.

As mentioned above, the ideology that created the myth of the black rapist relied on the gendered assumption that men are driven by their sexual desires and it is their civilization (i.e. race) that enables them to control those desires. By positing black men as savages, it was argued that they cannot control their desires and thus need to rape. Another implication was that since blackness was coded as ugly, both for men and women, the hypersexual black man was more likely to go after a white woman, who at that point was (and to some extent now still is) the ideal of beauty. Though created at the end of the $19^{\text {th }}$ century, like other racial tropes, this myth has been perpetuated and affects today's racial dynamics. Davis observes that the myth was redeployed in the 1970s white feminist struggle against rape culture, thus solidifying the connection between black masculinity and sexual assault. The strength of that myth may also be illustrated with the coverage of the 1997 Nushawn Williams case. Williams was convicted as a sex offender for knowingly infecting his sexual partners with HIV. Though less explicit in invoking the black rapist myth, some media outlets even admitted that the reason why the case met with such interest was the fact that the Williams is black and his sexual partners were white (Neale 2006: 3-5).

It is important to note for the further discussion of the value of black life that as long as black people were slaves and considered valuable property they rarely or never fell prey to lynchings (Davis 1983: 183). Lynching as a cultural practice consolidated the racist belief in the worthlessness of black lives that haunts American society till now. Bederman also noted that the contemporary press coverage of lynchings both in the North and South presented the victims as weak, "savage, unmanly cowards who deserved their fates" (1995: 51). In fact the journalists established their own masculinity in opposition to both the black lynch victim and the lynch mob (1995: 51).

These images of threatening, hypersexualized, yet lazy and intellectually inferior black men circulate in contemporary racial imagery and fuel not only white prejudice but also, as diagnosed by hooks, black attitudes. She concludes her discussion of representations of masculinity thus: 
Unfortunately, black people have not systematically challenged these narrow visions, insisting on a more accurate 'reading' of black male reality. Acting in complicity with the status quo, many black people have passively absorbed narrow representations of black masculinity, perpetuated stereotypes, myths, and offered one-dimensional accounts. Contemporary black men have been shaped by these representations. (hooks 1992: 89)

hooks's accurate diagnosis of the present condition explains the ways in which the stigmas of blackness and fatness overlap to further oppress the already disenfranchised population. It would, however, be inaccurate to argue that nothing has changed in popular representations of blackness since the 1990s.

Though there has been little change in terms of the systemic and institutional discrimination of minorities in the United States, there has been more diversity in terms of representation. Nevertheless, authors such as Mark Anthony Neal argue that in the $21^{\text {st }}$ century the American black male is in crisis and should reexamine his investments. ${ }^{28}$ Neal shifts the focus from the hip hop culture thug, who was often central to modern discussions of black male crisis, to the member of the black middle class (2006: 3). Prior to Neal's reworking of the black masculine types, Matthew Henry, in an analysis of the 2000 remake of the blaxploitation film Shaft, mentioned other tropes of black masculine representation: the criminal, gangster, and pimp. Henry argues that the 1970s culture created a new model of black masculinity that hip hop culture invoked in the 1990s, but whereas the original blaxploitation hero had elements of political consciousness, the revamped one was a retrograde apolitical creation (2004: 121). The content of the tropes and their variety might have changed. It seems, however, that those racist tropes did not vanish and continue to be invoked. They often masquerade as something else, as may be illustrated in the raced discourse on of the obesity epidemic, which tends to target minorities without explicitly addressing race.

${ }^{28}$ I agree with Bederman (1995), Kimmel (1994), and Carroll (2011) who posit that masculinity is never in crisis, as a crisis would suggest that masculinity or manhood is a fixed, essential category, thus I am not convinced by Neal's narrative of a black male crisis. Nevertheless, his account of modern black masculinity is an important voice in the discussion of black masculinities. Also see footnote 23. 


\section{Black Fatness and Fat Blackness}

Though both blackness and fatness are internally contradictory and overdetermined by a racist and sizeist culture, they are also complicit in maintaining the hierarchies which reinforce them. For example, the predominantly white fat studies may see black fatness as somehow more natural. Alternatively, fat studies may seek proof of othering practices of fatness in their relation to race, thus exoticizing the fatness of the other. A passage in Monaghan's Men and The War on Obesity does just that:

Crucially, if sizeism is also comparable to racism (Cooper 1998) then it is telling that race has been understood historically as a hierarchy of bodies and the hierarchical ordering of masculinities. As discussed by Connell (2000: 61) in relation to imperialism, this positioning has in some circumstances resulted in the 'feminization' of colonized men and 'in many parts of the colonized world indigenous men were called 'boys.' (2008: 23)

But is it possible to maintain the comparison between sizeism and racism suggested by Cooper? It seems that assuming a similarity of experience and projecting the platonic ideal of sizeist oppression indiscriminately of racial embodiment further alienates groups that should be included in the anti-oppression discourse. Thus an ideal analysis would avoid pitching racial markedness as an additional variable, a separate category, but engage in an intersectional approach.

In his account of masculinities Todd Reeser insists that "race should not be a later addition to the study of masculinity . . . but should in some way be part of any study of gender. Gender and race are so often connected and dependent on each other that it is difficult to talk about one without talking about the other" (2010: 144). Thinking along similar lines, Farell points out that

many scholars have observed that fat denigration seems to have had less hold among people of color in both the United States and England, usually citing either the existence of more pressing issues of survival or simply a different standard of beauty ... a greater tolerance for corpulence has something to do with the racial identities and experiences of people of color. What has not been explored, however, is the way that the denigration of fatness is intricately linked 
to the racial identities and experiences of white people in the United States and England. ... Nineteenth-century thinking about the 'natural' evolution of human races into stages of civilization meant not just the complex articulation of racial, gender, and sexual hierarchies, but also the construction of certain types of body types as superior. (2011: 59-60)

I suggest the need for examining the similarities and differences in meanings assigned to bodies perceived as black or fat and ways in which they inform or contradict one another. This approach will show also where the two overlap, but will not be an attempt to use one category as a metaphor for the other.

One major difference between racist accounts of blackness and sizeist accounts of fatness is that despite current investigations into the causes of obesity, centered on either genetics or infections (Gilman 2010: 114-20), ${ }^{29}$ and despite the "obesity epidemic's" metaphor of fat people as helpless victims (Berlant 2011: 95-7), ${ }^{30}$ the popular assumption is that one becomes fat $^{31}$ but one is born black. As such, the stigmatization of fatness results from an assumption that a persons' fat is a direct result of a mental or behavioral flaw, which manifests itself on the body. By contrast, race which is seen as inherent, ${ }^{32}$ suggests to the bigoted that a racially marked person is already located in a hierarchy of bodies and shares the hodgepodge of traits the racists society ascribes to that particular pigmentation. Fatness is seen as individual failure in a culture that prizes personal responsibility, whereas race is a social position that precludes agency. Surprisingly both locate a body in a hierarchy that justifies discrimination and both function as figures of excess, which within

\footnotetext{
${ }^{29}$ When discussing depression and the obesity epidemic, Berlant notes that both share an element of genetic explanation, which goes against corporate and personal responsibility accounts, and renders causality moot. While the genetic explanation is an attempt to deshame stigmatized people, it obscures other impersonal factors, contributing to obesity such as poor life quality (2011: 110).

${ }^{30}$ See also Monaghan and his discussion of Sontag's Illness as Metaphor: "Susan Sontag describes the harmful meanings our culture has imposed on tuberculosis, cancer, and AIDS. She points out that we often associate certain diseases with specific types of personalities, blaming the victims and shaming them into silence. In a similar vein, I would argue that we have imposed equally dangerous cultural meanings onto fatness. Fatness in the United States 'means' excess of desire, of bodily urges not controlled, of immoral, lazy, and sinful habits. Much more than a neutral description of a type of flesh, fatness carries with it such stigma that it propels us to take drastic, extreme measures to remove it" (2008: 10).

${ }^{31}$ Nathaniel C. Pyle and Michael I. Loewy observe that within homophobic and sizeist societies fatness (like queerness) is perceived as a choice and that discrimination of it is justified by the logic: if people tried hard enough they could change in order to conform to the norm (2009: 144).

${ }^{32}$ The inherence of race is a perniciously resistant presumption that survived its complete disproval in contemporary scholarship.
} 
patriarchal logic is a failure of normative masculinity seen as white (Gilman 2004: 28), ablebodied and athletic.

When considering fat black masculinity and excess, perceptions of sexuality seem a good starting point. The too-muchness of blackness leads to the image of hypersexuality, while the toomuchness of fatness may code effeminacy, emasculation, and asexuality. Todd W. Reeser observes that due to the image of a black man as well-endowed, in a phallocentric society

he might be taken to be excessively violent or excessively sexual. . . . The AfricanAmerican man is so gendered or so sexualized, or so the racist logic goes, that he is unable to control himself since he wants to have sex, to break into houses, or to rape women. The man of excess, then, can be just as subject to the rule of hegemonic masculinity as the effeminate man, and consequently, the construct of non-excessive or moderate applies to the white man or to another racialized group seen as ideal by contrast ... the implied contrasting man or group of men or people - the moderate one or the one in control - is justified in attempting to control black men, whether by simply watching him closely on the street or by incarcerating him where possible. (2010: 149-50)

Reeser adds that the perceived excess of masculinity is transformed into a lack, and in the case of African American masculinity, the lack in question is that of control over sexuality and violence (2010: 150). The white man is therefore positioned as the one in control, but also charged with the necessity to violently curb black hypersexuality. This, in turn, done symbolically through various practices of institutionalized and systemic racism, is a means of emasculating black men ${ }^{33}$ (contrary to the effeminating effect achieved through the earlier image of the docile slave, who was infantilized and rendered asexual).

Fatness also challenges the perception of virility, but the starting point is that an excess of fat signals a lack of sexuality. I have mentioned above that in a sizeist culture the smallness of the penis ascribed to fat men takes away their manliness. When discussing representations of fat

${ }^{33}$ A poignant discussion of black masculinity may be found in Philip Brian Harper's Are We Not Men?: Masculine Anxiety and the Problem of African-American Identity, who rejects the discourse of crisis to examine and challenge the notions of authenticity and manhood conveyed in the label "black." 
masculinity in the post-second wave 1970s television, Mosher observes that the "fat and flaccid male body proved to be a handy visual metaphor for the impotence of patriarchal power and masculinity under siege: large and vulnerable, the fat male body became a recognizable symbol of insecure male performativity, its phallic potential buried under folds of flesh." He adds that there was an effort to suppress fat sexuality for fear of grotesqueness (2001: 170-171). ${ }^{34}$

What happens then to black hypervirility when it meets fat flaccidity? According to the almost color-blind account offered by Mosher, for African American characters "[f]at provided a convenient, visible 'softening.' . . . In this infantilizing strategy, the fat body served to contain excessive orality, implying that such characters were not threatening but rather were 'all mouth,' and thus incapable of action" (2001: 175). ${ }^{35}$ As was suggested in the discussion of racial imagery on food packaging above, this is not the first time blackness is reduced to orality. Though Mosher does not mention such a possibility, it seems that the softening of the characters was meant as a counter-image to the athletic hypervirile and violent protagonists of blaxploitation cinema popular at that time (which in later decades evolved into the black action hero and the gangster). Mosher argues that in the gradually fattening society fat black men are a figure of contradiction, both as representations of the average (less policed and self-conscious) body, and a figure of deviancy if put in any potentially risky context.

Monaghan and Malson provide a different view of embodied fat black masculinity on the basis of one of their study's interviewees, Lenny, who by his own admission considered himself both "capable and sexually desirable." Yet, as Monaghan and Malson note, Lenny's reading of himself changed according to the context in which he found himself. The sexually confident bigness had to be dialed down in the company of predominately white middle-class women:

\footnotetext{
${ }^{34}$ Instead fat continued to be a source of humor (a trope not discussed here due to limitations of space). Fat sex also runs the risk of seeming deviant as noted by both Neda Ulaby in her account of the Arbuckle Scandal, and Pyle and Loewy in their account of fatness and homosexual desire.

${ }^{35}$ Mosher notes that these characters were accused of being a rehash of minstrel characters. Kyla Wazana Tompkins offers an interesting corollary to this analysis, when she observes that "the common representation of African Americans as eaters as well as food to be eaten opens up ambivalent possibilities inherent in a civic order sutured by Civil War and torn between segregation and limited political suffrage for blacks. Thus if black appetite and black bodies evoke the comedy of the eater being eaten, they cannot fail also to represent the black subject taking, as it were, a bite of the world" (2012: 172).
} 
Lenny, as the marginalized student rather than happy husband, presents a distinctly negative construction of the 'big black guy.' In this account, his bigness still signifies masculinity but its articulation as hypermasculine (in terms of racist 'gangster' stereotypes and other prejudices) 'spoils' his identity, positioning him as threatening and possibly criminal. His racialized size is made to signify a very negatively construed (stigmatized rather than valued) masculinity. (2013: 308, emphasis added)

Lenny's example illustrates the fact that the emasculating effect postulated by Mosher is not as straightforward when black fat masculinity is discussed. Bell and McNaughton recall Joan Gross's point that in hip hop culture fatness is considered hypermasculine. Gross argues that "in this definition masculinity is control - being in control of other men, women, and financial resources. Through brute force, which is closely correlated with body size, men gain respect and access to wealth. Literally and figuratively they can throw their weight around. Fatness is not viewed as a sign of lack of control but as a means by which control is attained" (qtd. in Bell and McNaughton 2007: 125)

Importantly, both Gross and Monaghan show that within black culture, power, virility, and size are supposedly connected with the ability to exert violence. Intimidation and domination are coded as masculine. This leads to the second dimension of fat black masculinity, i.e. its relation to threat. Within the racist logic that sponsored the creation of the myth of the black sexual predator, and later the black gangster, ${ }^{36}$ preemptive violence towards black men was justified by the threat they supposedly posed. Yet the ability to pose a threat is part of the positively-coded notions of black fatness. Hence the bigger the black man the scarier he seems to the racist onlooker. Confirmation of this stereotype can be found in justifications of the excessive use of violence by police officers involved in the deaths of Eric Garner and Michael Brown. The size of the men was cited to legitimate the excessive force used.

Thus the racist trope of the scary big black man is extended to include the notion that the fatter the black alleged "assailant" is, the more force the police should use. This questionable logic was used

${ }^{36}$ This is not to say that black men have had no control over their representation and may have purposefully or inadvertently contributed to the perpetuation of some characteristics associated with black masculinity. See Harper's Are We Not Men? 
to explain why Garner had to be detained by six officers, and why Darren Wilson, Michael Brown's killer, had to shoot him. Interestingly, the moment it turned out, as in the case of Eric Garner, that the victim was ill and therefore not a threat, the other prejudices connected with fatness kicked in. The logic seemed to shift from "the person is black and big, so he must be dangerous" to "fat (implicitly poor and lazy) people are responsible for their failing health that contributes to their earlier deaths." Just as in the case of Lenny, who felt sexy in his domestic, predominately black context, the unarmed big black man is powerful and important only in the context of his community. The moment he is faced with the racially biased law enforcement, his bigness is deployed as yet another justification for violence and surveillance. This time there is no masculine dividend involved.

This brings the discussion to its final point connecting race, fatness, and disability. ${ }^{37}$ In the sections above I attempted to discuss the commonalities and contradictions of meanings ascribed to black and fat male bodies. In conclusion, I want to suggest how the social hierarchy and institutionalized racism contribute to the further marginalization of poor people of color. Berlant observes that poverty malnourishes both the emaciated and the fat, and, as such, contributes to the slow death of these populations (2011: 107). She opposes the idea inherent to fat activism that being fat is unquestionably a position of resistance (2011: 107). Fat studies and fat activism have a positive potential that may eventually disturb and denaturalize the notion that fatness equals ugliness, laziness, illness or desexualization. Fat studies may help challenge the medicalization of fatness that so often translates into systemic discrimination of those diagnosed as obese. Body positivity movements may challenge beauty norms. At the same time, fat studies have so far done little to prevent institutional and interpersonal physical and psychological violence that affects the lives of

${ }^{37}$ Fatness is often conceived as a disability (see Perry 2014). There is still little research done specifically on disability and fatness other than fatness as disability. Some scholars, including Gilman, concur that "morbid obesity" is a disability as it fits the description of this condition: people with morbid disability "continually encounter various forms of discrimination, including outright intentional exclusion, the discriminatory effects of architectural, transportation, and communication barriers, overprotective rules and policies, failure to make modifications to existing facilities and practices, exclusionary qualification standards and criteria, segregation, and relegation to lesser services, programs, activities, benefits, jobs, or other opportunities" (2004: 14-5). What I am trying to show in the present article is that it is not enough to extend a category to include another type of body (fatness to include black fatness or male fatness), but to examine the criteria that lead to the ignorance of that body in the first place (blackness as the permanent other in white academia). What is more, though both disability studies and fat studies have overlapping interests and represent people who suffer from both sizeism and ableism, it would be a mistake to consider the two disciplines as variants of each other. Though they are both invested in challenging the notions of norms, they target specific iterations of normativity and prescription. Fat people might be discriminated because of their weight, though the images invoked may not relate to illness. 
those discriminated in a racist or sizeist society. ${ }^{38}$ It seems that because fat studies have operated under the assumption that racial difference is just another factor of oppression, they have offered little fine-tuned analysis of fat black bodies.

Though the value of anti-assimilationist moves allowing an African American woman to reject white patriarchal forms of beauty is unquestionable, it still does not enable her to overcome institutional and social obstacles created by a sexist, racist, sizeist and ableist society. The fact that a fat black man might be considered attractive within a subculture does not mean that he will be less harassed by law enforcement. Race, size or ability should not function as metaphors for one another, but should inform the intersectional study of each embodiment. I have attempted to indicate ways in which the fatness of the black male body may simultaneously connote power, status, and vulnerability to violence. It may be seen as capable of inflicting violence, especially sexual violence, while at the same time provoking violence towards itself. Consequently, some combinations of intersectional oppression do not just put people on a trajectory of a "slow death"; the conflation of racist, sizeist, ableist, and classists assumptions shifts them to a trajectory of "accelerated death," as exemplified by the deaths of Michael Brown, Eric Garner, and countless others continuously added to the Killed by Police list.

\section{Note}

I would like to thank the reviewers of this article for their criticism, which helped me sharpen my argument. Antoni Górny shared with me his knowledge of the history of blackness and saved me from many embarrassing typos.

\section{Works Cited}

"2014." Killed by Police. Web. 31 Oct. 2015 <http://www.killedbypolice.net/kbp2014.html>.

Alexander, Michelle. The New Jim Crow: Mass Incarceration in the Age of Color Blindness. New York: The New Press, 2010.

Baldwin, James. 2015. James Baldwin Tells Us All How to Cool It This Summer. 1968. Esquire 29 Apr. 2015. Web. 1 May 2015 <http://www.esquire.com/news-politics/interviews/a23960/jamesbaldwin-cool-it/>.

38 It should be noted that fat activism done mostly online seems more progressive and inclusive than scholarship, but this might be due to the difference in the paces at which each medium publishes. 
Bederman, Gail. Manliness and Civilization: A Cultural History of Gender and Race in the United States 1880-1917. Chicago: University of Chicago Press, 1995.

Bell, Kirsten, and Darlene McNaughton. "Feminism and the Invisible Fat Man." Body and Society 13 (2007): 107-131.

Ben-Moshe, Liat. "The Institution Yet to Come': Analyzing Incarceration Through a Disability Lens." The Disability Studies Reader. Ed. Lennard J. Davis. New York: Routlege, 2013. 132-143.

Berlant, Lauren. "Slow Death (Obesity, Sovereignty, Lateral Agency)." Cruel Optimism. Durham: Duke University Press, 2011. 95-119.

Biltekoff, Charlotte. "The Terror Within: Obesity in Post 9/11 U.S. Life." American Studies 48.3 (2007): 29-48.

Bouie, Jamelle. "Michael Brown Wasn't a Superhuman Demon." Slate 26 Nov. 2014. Web. 1 May 2015.

<http://www.slate.com/articles/news_and_politics/politics/2014/11/darren_wilson_s_racial

_portrayal_of_michael_brown_as_a_superhuman_demon.html $>$.

Carroll, Hamilton. Affirmative Reaction: New Formations of White Masculinity. Durham: Duke University Press, 2011.

"The Daily Show - We Can't Breathe." YouTube video, 2014. Comedy Central. <https://youtu.be/w8KqDIPdCOg> 1 May 2015.

Davis, Angela. "Rape, Racism and the Myth of the Black Rapist." Women, Race and Class. New York: Random House, 1983. 172-201.

Dyer, Richard. White. London: Routledge, 1997.

Ethnic Notions. Dir. Marlon Riggs. USA/Canada: Signifyin' Works/KQED, 1987.

Farell, Amy Erdman. Fat Shame: Stigma and the Fat Body in American Culture. New York: New York University Press, 2011.

Foner, Eric, Garraty, John A. The Reader's Companion to American History. New York: Houghton Mifflin Co., 1991.

Forth, Christopher E. "'Nobody Loves a Fat Man': Masculinity and Food in Film Noir." Men and Masculinities 16:4 (2013): 387-406.

Gaily, Jeannine A. The Hyper(in)visible Fat Woman: Weight and Gender Discourse in Contemporary Society. New York: Palgrave, 2014.

Gilman, Sander L. Fat Boys: A Slim Book. Lincoln: University of Nebraska Press, 2004.

---. Obesity: The Biography. Oxford: Oxford University Press, 2010.

Gross, Joan. "Phat." Fat: The Anthology of an Obsession. Eds. Don Kulick and Anne Meneley. New York: Penguin, 2005. 63-76.

Harris, Cheryl. "Whiteness as Property." Critical Race Theory: The Kew Writings That Formed the Movement. Eds. Kimberle Crenshaw et al. New York: The New Press, 1995. 279-291.

Harper, Philip Brian. Are We Not Men?: Masculine Anxiety and the Problem of African-American Identity. New York: Oxford University Press, 1996.

Henry, Matthew. 2004. "He Is a 'Bad Mother*\$\%@!\#': 'Shaft' and Contemporary Black Masculinity." African American Review 38.1 (Spring 2004): 119-126: Web. 2 Nov. 2015. 
hooks, bell. "Reconstructing Black Masculinity." Black Looks: Race and Representation. Boston: South End Press, 1992. 87-114.

Hutchinson, Earl Ofari. "The Criminalization of Black Men." MultiAmerica: Essays on Cultural wars and Cultural Peace. Ishmael Reed. New York: Penguin, 1998. 417-424.

Khazan, Olga. 2014. "Fat Shaming Eric Garner." The Atlantic 14 Dec. 2014. Web. 1 May 2015 <http://www.theatlantic.com/health/archive/2014/12/fat-shaming-eric-garner/383416/>.

LeBesco, Kathleen. Revolting Bodies?: The Struggle to Redefine Fat Identity. Amherst: University of Massachusetts Press, 2004.

Lemelle, Anthony J. Black Masculinity and Sexual Politics. New York: Routlege, 2010.

Lipsitz, George. Possessive Investment in Whiteness. Philadelphia: Temple University Press, 1998.

Lukin, Josh. "Disability and Blackness." The Disability Studies Reader. Ed. Lennard J. Davis, New York: Routlege, 2013. 308-315.

McEwan, Melissa. "Today at the Intersection of Racism and Hatred." Shakesville 4 Dec. 2014. Web. 3 Nov. 2015 <http://www.shakesville.com/2014/12/today-at-intersection-of-racism-andfat.html>.

Monaghan, Lee F. Men and The War on Obesity: A Sociological Study. London: Routlege, 2008.

Monaghan, Lee F., and Helen Malson. "'It's worse for women and girls': Negotiating Embodied Masculinities through Weight-related Talk." Critical Public Health 23:3 (2013): 304-319.

Morgan, Joan. "Fly-Girls, Bitches, and Hoes: Notes of a Hip Hop Feminist." Social Text 45 (Winter 1995): 151-157.

Mosher, Jerry. "Setting Free the Bears: Refiguring Fat Men on Television." Bodies Out of Bounds: Fatness and Transgression. Eds. Jana Evans Braziel and Kathleen LeBesco. Berkley: University of California Press, 2001. 166-196.

Morris, Susan Booker. "Targeting Black Masculinity: An Analysis of the (mis)Representation of Black Men in the History of Early American Popular Culture." Interdisciplinary Humanities: (mis)Representation of Difference 28.2 (2011): 77-87.

Lesbian, Gay, Bisexual, Tansgender, Queer and HIV-Affected Hate Violence Report 2013. National Coalition of Anti-Violence Project. 2014. New York: NCAVP. Web. < http://www.avp.org/>.

Neal, Mark Anthiny. New Black Man. New York: Routledge, 2006.

Painter, Nell Irvin. The History of White People. New York: WW Norton \& Company. 2010.

Perry, David M. "When disability and race intersect." CNN iReport 4 Dec. 2014. Web. 15 Nov. 2015 <http://edition.cnn.com/2014/12/04/opinion/perry-garner-disability-raceintersection/index.html?sr=sharebar_facebook $>$.

Pyle, Nathaniel C., and Michael I. Loewy. "Double Stigma: Fat Men and Their Male Admirers." The Fat Studies Reader. Eds. Esther Rothblum and Sandra Solovay. New York: New York University Press, 2009. 143-150.

Reeser, Todd W. Masculinities in Theory: An Introduction. Malden: Blackwell Publishing, 2010.

Scott, Darieck. Extravagant Abjection: Blackness, Power, and Sexuality in the African American Literary Imagination. New York: NYU Press, 2010. 
Tompkins, Kyla Wazana. Racial Indigestion: Eating Bodies in the 19th Century. New York: New York University Press, 2012.

Ulaby, Neda. "Roscoe Arbuckle and the Scandal of Fatness." Bodies Out of Bounds: Fatness and Transgression. Eds. Jana Evans Braziel and Kathleen LeBesco. Berkley: University of California Press, 2001. 153-166.

Witt, Doris. Black Hunger: Soul Food and America. Minneapolis: University of Minnesota Press, 1999. 